\title{
Neonatal Neutrophils with Prolonged Survival Secrete Mediators Associated with Chronic Inflammation
}

\author{
Caroline N. Nguyen ${ }^{a}$ Patricia M. Schnulle ${ }^{a}$ Nasser Chegini ${ }^{b} \quad$ Xiaoping Luo $^{b}$ \\ Joyce M. Koenig ${ }^{a, c}$ \\ Departments of a Pediatrics and ${ }^{\mathrm{b}}$ Obstetrics and Gynecology, University of Florida, Gainesville, Fla., and \\ 'Department of Pediatrics, Saint Louis University, St. Louis, Mo., USA
}

\section{Key Words}

Neutrophil · Survival · Cytokine · IL-8 · MIP-1 · IL-1Ra • Inflammation

\begin{abstract}
Background: The resolution of inflammation involves the efficient removal of apoptotic neutrophils (PMN). However, a subpopulation of PMN that are resistant to apoptosis may contribute to PMN persistence in tissues, an early hallmark of chronic inflammation. We previously made observations that neonatal PMN with prolonged survival had augmented expression of $C D 18 / C D 11 b$, an adhesion molecule critical to inflammation. Objectives: The objectives of this study were to test the hypothesis that surviving neonatal PMN retain the capacity to secrete key mediators associated with chronic inflammation. Methods: We profiled cytokine and chemokine secretion patterns of lipopolysaccharide (LPS)-stimulated neonatal and adult PMN using multicytokine array and ELISA. Results: We observed that surviving 24-hour neonatal PMN stimulated with LPS had enhanced secretion of interleukin (IL)-8, a chemokine involved in PMN activation and recruitment. In addition, 24-hour neonatal PMN secreted levels of monocyte inhibitory protein (MIP)- $1 \beta$ that were higher than those secreted by 0 -hour PMN, but amounts of IL-1 receptor antagonist (IL-1Ra) were lower. Conclusions:
\end{abstract}

The results of the present study extend previous observations of augmented function in surviving neonatal neutrophils, and further suggest their potential contribution to the pathogenesis of inflammatory disorders in neonates.

Copyright $\odot 2010$ S. Karger AG, Basel

\section{Introduction}

The prolonged survival of inflammatory neutrophils, which is associated with their delayed removal from tissues, is a critical component in the pathogenesis of chronic inflammatory and autoimmune disorders in adults [1-4] and neonates [5-8]. The accumulation of tissue neutrophils, a hallmark of the early phase of chronic inflammation, can mediate injury through two related processes: (1) the recruitment and activation of additional neutrophils from the circulation, and (2) the delayed clearance of neutrophils with inflammatory or cytotoxic function [9-12]. Neutrophils activated by an inflammatory milieu can produce cytokines and cytotoxic factors which can also enhance continued inflammation and promote lung injury [13-16]. Neonatal leukocytes have also been shown to produce IL- $8[17,18]$, a chemokine closely associated with the pathogenesis of chronic inflammatory disorders [19-21].

\section{KARGER}

() 2010 S. Karger AG, Basel

Fax +41613061234 E-Mail karger@karger.ch www.karger.com www.karger.com/neo
Joyce M. Koenig, MD

Division of Neonatology, Department of Pediatrics

E. Doisy Research Center, Saint Louis University

1100 S. Grand Blvd., St. Louis, MO 63104 (USA)

Tel. +1 314977 9291, Fax +1 314977 9105, E-Mail koenijm@ @lu.edu 
Exposure of neutrophils to bacterial components or cytokines can prolong their longevity, and these surviving neutrophils retain inflammatory and cytotoxic functions, including the secretion of critical mediators [2224]. However, less information exists regarding neutrophils that survive spontaneous apoptosis in the absence of survival factors, which may also represent the subpopulation of neutrophils with the capacity for very prolonged survival with intact inflammatory function [24]. Savill et al. [3] originally observed that a small proportion of neutrophils from adult donors are intrinsically resistant to spontaneous apoptosis. In contrast, we and others reported that a relatively larger subpopulation of neutrophils with preferential survival exists in neonates $[25,26]$.

Studies by Dransfield et al. [27] suggested that surviving nonapoptotic neutrophils retained selectin- and integrin-mediated adherence. We previously reported that neonatal neutrophils enriched for this nonapoptotic population had robust upregulation of the adhesion molecule, CD18/CD11b, in addition to reactive oxygen intermediate production in response to stimulation [28]. Given the likely contribution of these functions to inflammatory processes $[29,30]$, we wondered whether neonatal neutrophils with prolonged survival might retain inflammatory potential. The goal of the present study was to test our hypothesis that neonatal neutrophils which survive spontaneous apoptosis can secrete mediators with the capacity to amplify inflammation.

\section{Methods}

Neutrophil (PMN) Isolation and Culture

Samples from the umbilical veins of term placentas delivered after uncomplicated cesarean sections or from the peripheral venous blood of healthy adult volunteers were collected into heparinized syringes and processed immediately. Samples were obtained in accordance with the guidelines of the Institutional Review Board for Human Studies.

Dextran-sedimented leukocytes were subjected to density centrifugation, and the resultant neutrophils were subjected to hypotonic lysis of contaminating erythrocytes, as previously described $[31,32]$. Isolated PMN $\left(10^{6}\right.$ cells $\left./ \mathrm{ml}\right)$ suspended in RPMI1640/2\% FCS (Mediatech Inc., Herndon, Va., USA) were cultured in polypropylene tubes at $37^{\circ} \mathrm{C}, 5 \% \mathrm{CO}_{2}$ for $24 \mathrm{~h}$ to induce spontaneous apoptosis, as described below.

Enrichment of the Surviving, Nonapoptotic PMN Fraction

Nonapoptotic surviving neutrophils were separated from apoptotic neutrophils in 24-hour cultures using immunomagnetic techniques, as previously reported $[28,33]$. Briefly, cells removed from culture were stained with annexin V-PE (BD Biosciences Pharmingen, San Diego, Calif., USA). Neutrophils washed and resuspended in binding buffer were then stained with an an-
ti-PE-selection cocktail followed by incubation with magnetic nanoparticles (both, EasySep ${ }^{\mathrm{TM}}$, StemCell Technologies, Vancouver, B.C., Canada). The neutrophil-magnetic particle suspension was then placed in a magnet (EasySep ${ }^{\mathrm{TM}}$ ), as per the manufacturer's instructions, to enrich the cells for the nonapoptotic (annexin V-negative) fraction. Purity of the enriched neutrophil suspensions was $>95 \%$, as determined by flow cytometric analysis of eluted PMN by annexin V-PE staining. The resultant annexin Vnegative neutrophils were then cultured as described below.

LPS Stimulation of Neutrophil Cultures

Freshly isolated, 0-hour neutrophils or 24-hour annexin Vnegative (surviving) neutrophils (enriched as above) were incubated at a concentration of $1 \times 10^{6}$ cells $/ \mathrm{ml}$ at $37^{\circ} \mathrm{C}$ for $4 \mathrm{~h}$ in the presence of bacterial lipopolysaccharide (LPS, $10 \mathrm{ng} / \mathrm{ml}$; SigmaAldrich Inc., St. Louis, Mo., USA) or in media alone. After incubation, the cell-free supernatants were harvested and stored at $-80^{\circ} \mathrm{C}$ until assay.

Cytokine/Chemokine Profiling of PMN-Conditioned Media

Aliquots of conditioned media (culture supernatants) were thawed once and assayed in duplicate using a multiplex immunoassay cytokine/chemokine kit (Fluorokine ${ }^{\circledR}$ MAP MultiAnalyte Profiling, R\&D Systems, Minneapolis, Minn., USA) for the analysis of: ENA-78, FGFbasic, G-CSF, IFN- $\gamma$, IL-1 $\alpha$, IL-1 $\beta$, IL-1Ra, IL-2, IL-4, IL-5, IL-6, IL-8, IL-10, IL-17, MCP-1, MIP-1 $\alpha$, MIP-1 $\beta$, RANTES, TNF- $\alpha$, VEGF and TPO. The assays were performed on the Luminex 100IS platform (Luminex Corp., Austin, Tex., USA). Additional analyses of the cell-free supernatants (IL-6, sensitivity $>3.1 \mathrm{pg} / \mathrm{ml}$; IL-8, sensitivity $>31.2 \mathrm{pg} / \mathrm{ml}$ ) were performed by ELISA, according to the manufacturer's instructions (Quantikine ${ }^{\circledR}, \mathrm{R} \& \mathrm{D}$ Systems).

\section{Data Analysis}

Statistical comparisons between groups were made using Student's t test or the Mann-Whitney rank sum test for nonparametric data (SigmaStat ${ }^{\circledR}$ for Windows software, version 2.03, SPSS Inc.). $\mathrm{p}<0.05$ was considered to be statistically significant. Data are presented as the mean $\pm \mathrm{SD}$.

\section{Results}

\section{Neonatal and Adult Neutrophils Secrete a Variety of Inflammatory Mediators}

Cell-free supernatants were harvested from paired neonatal and adult neutrophil samples cultured in parallel for each of 5-9 separate experiments. Supernatants of LPS-stimulated freshly-isolated (0-hour) and nonapoptotic surviving (24-hour) neutrophil cultures were profiled for content of inflammatory mediators using multicytokine array or ELISA. Of the cytokines/chemokines tested, supernatants were found to contain only a subset of mediators at levels above the limits of sensitivity for the assay. Specifically, and as shown in table 1 and figures 1 and 2 , these mediators included proinflammatory cyto- 
Table 1. Values represent levels $(\mathrm{pg} / \mathrm{ml})$ of mediators in the culture supernatants of freshly-isolated ( 0 -hour) and 24-hour, annexin V-negative (nonapoptotic, surviving) PMN following LPS stimulation, as assayed by multicytokine array and/or ELISA and as described in the Methods section

\begin{tabular}{|c|c|c|c|c|c|c|}
\hline \multirow[t]{2}{*}{ Mediator } & \multicolumn{3}{|l|}{$0 \mathrm{~h}$} & \multicolumn{3}{|l|}{$24 \mathrm{~h}$} \\
\hline & AD PMN & CB PMN & $\mathrm{p}$ & AD PMN & CB PMN & $\mathrm{p}$ \\
\hline \multicolumn{7}{|l|}{ Chemokines } \\
\hline ENA-78 & $8 \pm 6$ & $12 \pm 6$ & 0.43 & ND & ND & - \\
\hline MCP-1 & $48 \pm 3$ & $51 \pm 60$ & 0.98 & ND & ND & - \\
\hline RANTES & $86 \pm 39$ & $200 \pm 94$ & 0.07 & $14 \pm 4$ & $17 \pm 4$ & 0.31 \\
\hline \multicolumn{7}{|l|}{ Cytokines } \\
\hline IL- $1 \alpha$ & $10 \pm 5$ & $16 \pm 2$ & 0.07 & $10 \pm 3$ & $11 \pm 5$ & 0.69 \\
\hline IL- $1 \beta$ & $28 \pm 27$ & $18 \pm 9$ & 0.98 & ND & ND & - \\
\hline IL-6 & $14 \pm 5$ & $16 \pm 1$ & 0.62 & $9 \pm 4$ & $12 \pm 19$ & 0.64 \\
\hline TNF- $\alpha$ & $43 \pm 2$ & $65 \pm 13$ & 0.02 & ND & ND & - \\
\hline \multicolumn{7}{|c|}{ Anti-inflammatory mediators } \\
\hline IL-1Ra & $6,565 \pm 2,702^{*}$ & $7,149 \pm 992^{*}$ & 0.69 & $949 \pm 80$ & $992 \pm 235$ & 0.74 \\
\hline \multicolumn{7}{|c|}{ Angiogenic mediators } \\
\hline VEGF & $26 \pm 4$ & $52 \pm 26$ & 0.03 & ND & $7 \pm 1$ & - \\
\hline
\end{tabular}

Data represent the means \pm SD of data from 5 independent experiments using paired CB and AD PMN. $\mathrm{ND}=$ Levels below the assay limits of detection for that particular mediator. ${ }^{*} \mathrm{p}<0.05,0 \mathrm{~h}$ vs. 24-hour PMN.

kines (IL-1 $\alpha$, IL-1 $\beta$, IL-6, IL-8, TNF- $\alpha$ ), chemokines (ENA-78, MCP-1, MIP-1 $\beta$, RANTES), an angiogenic factor (VEGF) and an anti-inflammatory mediator (IL-1Ra).

\section{Surviving Neonatal Neutrophils Secrete Augmented \\ Levels of $I L-8$}

As shown in figure 1 , freshly-isolated (0-hour) neonatal neutrophils stimulated with LPS secreted markedly elevated levels of IL-8 [neonatal (CB), 1,317 \pm 466 vs. adult (AD), $170 \pm 71 \mathrm{pg} / \mathrm{ml} ; \mathrm{p}<0.001 ; \mathrm{n}=9$ separate studies of paired neonatal and adult neutrophils). Surviving (24-hour) neutrophils stimulated with LPS also secreted robust levels of IL-8, and again, neonatal neutrophils secreted relatively higher levels $(\mathrm{CB}, 1,773 \pm 827$ $\mathrm{pg} / \mathrm{ml}$ vs. AD, $1,097 \pm 462 \mathrm{pg} / \mathrm{ml} ; \mathrm{p}<0.01)$. The IL- 8 levels secreted by LPS-stimulated 0 -hour and surviving (24hour) neonatal neutrophils were not different $(\mathrm{p}=0.07)$. In contrast, stimulated surviving adult neutrophils secreted IL-8 at levels that were nearly sevenfold greater than levels secreted by freshly-isolated neutrophils $(\mathrm{p}<$ 0.01 ). We also examined the constitutive release of IL-8 by unstimulated 0 -hour and surviving (24-hour) PMN. Unstimulated 0-hour neonatal, but not adult, PMN secreted IL-8 (CB 0-hour, $39 \pm 52 \mathrm{pg} / \mathrm{ml}$ ). These levels were not significantly different from those secreted by surviving, 24-hour neonatal PMN $(148 \pm 100 \mathrm{pg} / \mathrm{ml}$ vs. $\mathrm{p}=$ 0.10). Surviving, 24-hour adult PMN also secreted IL-8 at

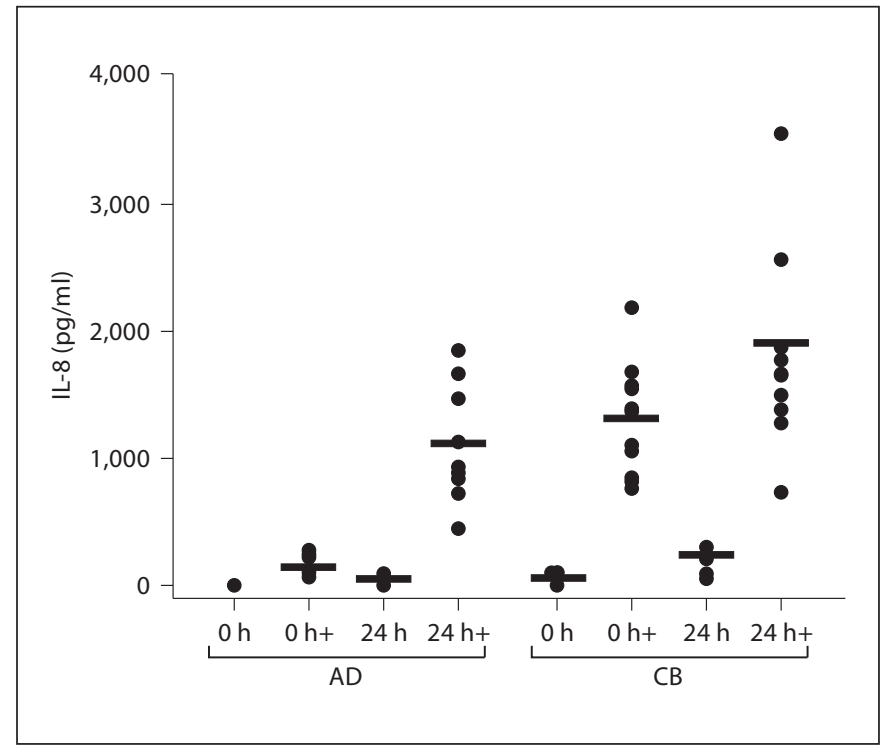

Fig. 1. IL-8 secretion by freshly-isolated and surviving PMN. In paired studies, AD and CB PMN that were freshly isolated (0hour), or enriched for the annexin V-negative (nonapoptotic, surviving) fraction (24-hour), were cultured for $4 \mathrm{~h}$ in the presence of LPS (10 ng/ml final concentration) or media alone, and the cellfree supernatants were tested for IL- 8 content. The graph represents individual data points derived from 5-9 separate studies of paired cultures of AD and CB PMN. Labels in the $\mathrm{x}$-axis represent cultures of 0 -hour and 24-hour PMN in media alone or in the presence of LPS (+). The horizontal bars represent the mean values for each data set. 


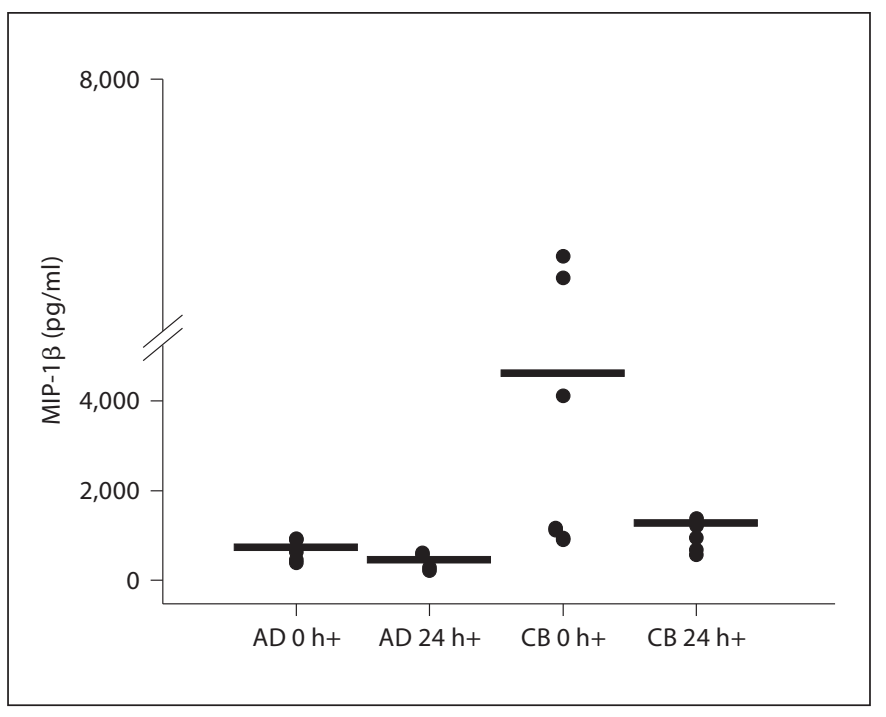

Fig. 2. MIP-1 $\beta$ secretion by freshly-isolated and surviving PMN stimulated with LPS. In paired studies, AD and CB PMN that were freshly isolated (0-hour), or enriched for the annexin V-negative (nonapoptotic, surviving) fraction (24-hour), were cultured for $4 \mathrm{~h}$ in the presence of LPS (10 $\mathrm{ng} / \mathrm{ml}$ final concentration) and the cell-free supernatants tested for MIP-1 $\beta$ content. The graph represents individual data points derived from 5 separate studies of paired cultures of $\mathrm{AD}$ and $\mathrm{CB}$ PMN. Labels in the $\mathrm{x}$-axis represent cultures of 0 -hour and 24-hour PMN in the presence of LPS $(+)$. The horizontal bars represent the mean values for each data set.

levels that tended to be lower compared to secretion by neonatal PMN, but which did not reach statistical significance $(49 \pm 37 \mathrm{pg} / \mathrm{ml}, \mathrm{p}=0.08$ vs. 24 -hour CB PMN).

\section{Surviving LPS-Stimulated Neonatal Neutrophils}

Secrete More of the Inflammatory Chemokine MIP-1 $\beta$

As shown in figure 2, LPS-stimulated 0-hour neonatal neutrophils tended to secrete higher levels of MIP-1 $\beta$ compared to 0 -hour adult neutrophils, although this did not reach statistical significance $(\mathrm{CB}, 4,089 \pm 3,154 \mathrm{vs}$. $\mathrm{AD}, 639 \pm 244 \mathrm{pg} / \mathrm{ml} ; \mathrm{p}=0.08)$. In contrast, stimulated surviving 24-hour neonatal neutrophils secreted more MIP-1 $\beta$ (961 \pm 339$)$ than did stimulated surviving adult neutrophils ( $277 \pm 36 \mathrm{pg} / \mathrm{ml} ; \mathrm{p}<0.01)$, but at levels that were not different from those secreted by 0 -hour adult neutrophils $(p=0.28)$. In contrast to the greater MIP-1 $\beta$ secretion observed in surviving (24-hour) versus freshlyisolated (0-hour) neonatal PMN, MIP-1 $\beta$ secretion by surviving adult PMN was significantly less than that by 0 -hour adult PMN $(\mathrm{p}<0.05)$.
Neonatal and Adult Neutrophils Secrete Similar

Amounts of IL-1Ra, IL- $1 \alpha$ and IL-6

Freshly-isolated (0-hour) neonatal and adult neutrophils stimulated with LPS secreted similar levels of the anti-inflammatory cytokine, IL-1Ra (table 1). LPS-stimulated surviving (24-hour) neonatal or adult neutrophils also secreted similar levels of IL-1Ra, although these were sixfold lower relative to levels secreted by 0 -hour neutrophils $(\mathrm{p}<0.05)$. In contrast, secretion of IL- $1 \alpha$ and IL- 6 by LPS-stimulated 0 -hour and surviving 24 -hour neonatal and adult neutrophils was similar between groups and time points (table 1).

Stimulated Surviving Neutrophils Secrete Lower or Negligible Levels of Other Inflammatory Mediators

Freshly-isolated (0-hour) neonatal neutrophils stimulated with LPS secreted higher levels of the inflammatory cytokine TNF- $\alpha$, but similar levels of IL- $1 \beta$ compared to stimulated 0 -hour adult neutrophils (table 1). Stimulated neonatal neutrophils (0-hour) also secreted relatively greater amounts of the chemokines MCP-1 and RANTES relative to levels secreted by stimulated 0 -hour adult neutrophils. In contrast, stimulation of surviving (24-hour) neonatal or adult neutrophils induced minimal or undetectable secretion of all four of these cytokines or chemokines.

Stimulation of freshly-isolated (0-hour) neutrophils with LPS also induced secretion of the angiogenic mediator, VEGF, at levels that were higher in neonatal neutrophils compared to those secreted by 0 -hour adult neutrophils (table 1). In contrast, surviving (24-hour) neonatal neutrophils secreted levels of VEGF that were lower compared to 0 -hour cultures $(\mathrm{p}<0.05)$ while VEGF secretion was undetectable in cultures of surviving adult neutrophils.

\section{Discussion}

The goal of the present studies was to profile the inflammatory mediators secreted by the subpopulations of neonatal and adult neutrophils that survive spontaneous apoptosis. Surviving neutrophils were observed to secrete several key chemokines with relevance to chronic inflammatory disorders, and this was more prominent for neonatal neutrophils.

Neonatal neutrophils (freshly-isolated, 0-hour) were induced by LPS to secrete elevated levels of IL-8, as shown in figure 1 and in confirmation of previous reports [18, 34]. In addition, surviving (24-hour) neutrophils exhib- 
ited a unique capacity to secrete IL-8 at levels that were at least similar to (neonatal neutrophils) or in excess of (adult neutrophils) levels secreted by freshly-isolated (0hour) neutrophils. Furthermore, secretion of IL-8 was particularly robust in LPS-stimulated surviving neonatal neutrophils, and was observed even under basal conditions. The C-X-C chemokine, IL- 8 , is a potent neutrophil chemoattractant that also enhances neutrophil function [35]. Thus, the present observations are consistent with our previous data showing augmented inflammatory function in surviving neonatal neutrophils [28]. Our observations also suggest that neutrophils are an important cellular source of the prominent IL-8 expression in neonates at risk for or affected by inflammatory or infectious disorders [18-21, 36-40].

Robust expression of IL-8 in neonatal neutrophils may be a reflection of age-specific neutrophil differences in the translational control of transcriptional events. In particular, Yost et al. [41] observed that IL-8 production by inflammatory neutrophils can be modulated through the retinoic acid receptor- $\alpha$ transcription factor, which is under the regulation of the signaling 12 kinase mammalian target of rapamycin (mTOR). Thus, the heightened expression of IL-8 in neonatal neutrophils may be related to alterations in regulatory signaling pathways. We recently reported prominent Akt-mediated survival signaling [42] and have observed a unique pattern of NF- $\kappa \mathrm{B}$-regulated function in neonatal neutrophils (manuscript in preparation). In contrast to the pattern of IL-8 secretion, surviving neutrophils released negligible amounts of other inflammatory cytokines, including IL- $1 \alpha$, IL-1 $\beta$, IL-6 and TNF- $\alpha$. The minimal secretion of these cytokines, also observed in freshly-isolated neutrophils [16], suggests that cells other than neutrophils may contribute to the high expression of IL- $1 \alpha$, IL- 6 and TNF- $\alpha$ associated with chronic inflammatory disorders [20, 43-45].

Freshly-isolated neonatal and adult neutrophils stimulated with LPS had marked secretion of MIP-1 $\beta /$ CCL4, a chemokine involved in the recruitment of monocytes and neutrophils to inflammatory sites [43, 46], and is an observation consistent with existing literature $[47,48]$. We also now report that surviving neonatal neutrophils could be induced to secrete MIP-1 $\beta$. Of note, surviving neonatal neutrophils secreted higher amounts of MIP-1 $\beta$ compared to secretion by freshly-isolated neutrophils, while secretion of MIP-1 $\beta$ was markedly downregulated in surviving adult neutrophils compared to adult 0 -hour neutrophils. Elevated expression of CCL4 has been observed in association with a variety of inflammatory disorders, including in the lungs [49-51]. Thus, the capacity of surviving neonatal neutrophils to secrete CCL4 may be an integral component of the proinflammatory phenotype that is suggested by the present study. In contrast, surviving neutrophils secreted minimal or undetectable amounts of the monocyte-specific chemokines, RANTES and MCP-1, an observation consistent with preferential recruitment of activated neutrophils [24, 52].

The present observations are consistent with accumulating evidence that immaturity of the neonatal innate immune system results in an imbalance that promotes inflammation $[34,53,54]$. The lower secretion of the anti-inflammatory mediator, IL-1Ra, could theoretically potentiate the proinflammatory phenotype of surviving neonatal neutrophils by downregulating inhibitory function [55]. In addition, recent data suggest that immaturity of Toll-like receptor signaling is associated with a pronounced inflammatory response in neonatal immune cells $[56,57]$.

The present studies provide novel evidence that surviving neonatal neutrophils can secrete mediators with the potential to promote continued neutrophil recruitment and to contribute to the establishment of chronic inflammatory processes. These data are consistent with observations by Chakravarti et al. [24] of a reprogrammed inflammatory phenotype in neutrophils with prolonged survival. Importantly, since a much larger subpopulation of neonatal neutrophils exhibit preferential survival compared to those of adult neutrophils [24-26,58], our data extend the concept that the neonatal innate immune response may amplify processes that promote inflammation-related morbidity and mortality $[28,59,60]$.

\section{Acknowledgments}

We wish to acknowledge Pam Connolly, RN, Ann Cothran, $\mathrm{RN}$, and the labor and delivery staff at the University of Flori$\mathrm{da}$ - Shands Hospital, as well as the parents of the cord blood donors and the adult donors, for helping us acquire the specimens needed to conduct our studies. We also thank William Keenan, $\mathrm{MD}$, for his thoughtful review of the manuscript.

\section{Statement of Financial Support}

This work was supported in part by grants from the National Institutes of Health (RO1 HD47401) and a University of Florida Clinical Research Center Grant (RR00082, both to J.M.K.). 


\section{References}

1 Savill J, Dransfield I, Gregory C, Haslett C: A blast from the past: clearance of apoptotic cells regulates immune responses. Nat Rev Immunol 2002;2:965-975.

-2 Tsujimoto H, Takeshita S, Nakatani K, Kawamura Y, Tokutomi T, Sekine I: Delayed apoptosis of circulating neutrophils in $\mathrm{Ka}$ wasaki disease. Clin Exp Immunol 2001;126: 355-364.

3 Savill JS, Wyllie AH, Henson JE, Walport MJ, Henson PM, Haslett C: Macrophage phagocytosis of aging neutrophils in inflammation. Programmed cell death in the neutrophil leads to its recognition by macrophages. J Clin Invest 1989;83:865-875.

4 Haslett C, Savill JS, Meagher L: The neutrophil. Curr Opin Immunol 1989;2:10-18.

$\checkmark 5$ Speer CP: New insights into the pathogenesis of pulmonary inflammation in preterm infants. Biol Neonate 2001;79:205-209.

-6 Kotecha S: Cytokines in chronic lung disease of prematurity. Eur J Pediatr 1996;155(suppl 2):S14-S17.

7 Kotecha S, Mildner RJ, Prince LR, Vyas JR, Currie AE, Lawson RA, Whyte MKB: The role of neutrophil apoptosis in the resolution of acute lung injury in newborn infants. Tho$\operatorname{rax} 2003 ; 58: 961-967$.

$\checkmark 8$ Oei J, Lui K, Wang H, Henry R: Decreased neutrophil apoptosis in tracheal fluids of preterm infants at risk of chronic lung disease. Arch Dis Child Fetal Neonatal Ed 2003; 88:F245-F249.

-9 Jones HA, Schofield JB, Krausz T, Boobis AR, Haslett C: Pulmonary fibrosis correlates with duration of tissue neutrophil activation. Am J Respir Crit Care Med 1998;158:620628.

-10 Serhan CN, Savill J: Resolution of inflammation: the beginning programs the end. Nat Immunol 2005;6:1191-1197.

-11 Matthay MA, Zimmerman GA: Acute lung injury and the acute respiratory distress syndrome: four decades of inquiry into pathogenesis and rational management. Am J Respir Cell Mol Biol 2005;33:319-327.

-12 Brown V, Elborn JS, Bradley J, Ennis M: Dysregulated apoptosis and NFkappaB expression in COPD subjects. Respir Res 2009;10: 24.

-13 Maloney CG, Kutchera WA, Albertine KH, McIntyre TM, Prescott SM, Zimmerman GA: Inflammatory agonists induce cyclooxygenase type 2 expression by human neutrophils. J Immunol 1998;160:1402-1410.

14 Knaapen AM, Schins RP, Polat D, Becker A, Borm PJ: Mechanisms of neutrophil-induced DNA damage in respiratory tract epithelial cells. Mol Cell Biochem 2002;234235:143-151.

15 Auten RL, Whorton MH, Nicholas MS: Blocking neutrophil influx reduces DNA damage in hyperoxia-exposed newborn rat lung. Am J Respir Cell Mol Biol 2002;26:391397.
6 Schröder AK, von der Ohe M, Kolling U, Altstaedt J, Uciechowski P, Fleischer D, Dalhoff K, Ju X, Zenke M, Heussen N, Rink L: Polymorphonuclear leucocytes selectively produce anti-inflammatory interleukin-1 receptor antagonist and chemokines, but fail to produce pro-inflammatory mediators. Immunology 2006;119:317-327.

17 Schultz C, Rott C, Temming P, Schlenke P, Moller JC, Bucsky P: Enhanced interleukin- 6 and interleukin- 8 synthesis in term and preterm infants. Pediatr Res 2002;51: 317-322.

18 Huang HC, Tai FY, Wang FS, Liu CA, Hsu TY, Ou CY, Yang KD: Correlation of augmented IL-8 production to premature chronic lung disease: implication of posttranscriptional regulation. Pediatr Res 2005 58:216-221.

19 Kotecha S, Chan B, Azam N, Silverman M, Shaw RJ: Increase in interleukin- 8 and soluble intercellular adhesion molecule-1 in bronchoalveolar lavage fluid from premature infants who develop chronic lung disease. Arch Dis Child Fetal Neonatal Ed 1995 72:F90-F96

20 Speer CP: Inflammation and bronchopulmonary dysplasia: a continuing story. Semin Fetal Neonatal Med 2006;11:354-362.

-21 Ambalavanan N, Carlo WA, D’Angio CT, McDonald SA, Das A, Schendel D, Thorsen P, Higgins RD: Cytokines associated with bronchopulmonary dysplasia or death in extremely low birth weight infants. Pediatrics 2009; 123:1132-1141.

22 Lee A, Whyte MK, Haslett C: Inhibition of apoptosis and prolongation of neutrophil functional longevity by inflammatory mediators. J Leukoc Biol 1993;54:283-288.

23 Colotta F, Re F, Polentarutti N, Sozzani S, Mantovani A: Modulation of granulocyte survival and programmed cell death by cytokines and bacterial products. Blood 1992 80:2012-2020.

24 Chakravarti A, Rusu D, Flamand N, Borgeat P, Poubelle PE: Reprogramming of a subpopulation of human blood neutrophils by prolonged exposure to cytokines. Lab Invest 2009;89:1084-1099.

25 Allgaier B, Shi M, Luo D, Koenig JM: Spontaneous and Fas-mediated apoptosis are diminished in umbilical cord blood neutrophils compared with adult neutrophils. I Leukoc Biol 1998;64:331-336.

-26 Hanna N, Vasquez P, Pham P, Heck DE, Laskin JD, Laskin DL, Weinberger B: Mechanisms underlying reduced apoptosis in neonatal neutrophils. Pediatr Res 2005;57:56-62.

27 Dransfield I, Stocks SC, Haslett C: Regulation of cell adhesion molecule expression and function associated with neutrophil apoptosis. Blood 1995;85:3264-3273.
28 Koenig JM, Stegner JJ, Schmeck AC, Saxonhouse MA, Kenigsberg LE: Neonatal neutrophils with prolonged survival exhibit enhanced inflammatory and cytotoxic responsiveness. Pediatr Res 2005;57:424-429.

29 Smith CW: Endothelial adhesion molecules and their role in inflammation. Can J Physiol Pharmacol 1993;71:76-87.

30 Chabot F, Mitchell JA, Gutteridge JM, Evans TW: Reactive oxygen species in acute lung injury. Eur Respir J 1998;11:745-757.

-31 Dransfield I, Buckle AM, Savill JS, McDowall A, Haslett C, Hogg N: Neutrophil apoptosis is associated with a reduction in CD16 ( Fc gamma RIII) expression. J Immunol 1994; 153:1254-1263.

32 Koenig JM, Simon J, Anderson DC, Smith E, Smith CW: Diminished soluble and total cellular L-selectin in cord blood is associated with its impaired shedding from activated neutrophils. Pediatr Res 1996;39:616-621.

33 Dransfield I, Buckle AM, Savill JS, McDowall A, Haslett C, Hogg N: Neutrophil apoptosis is associated with a reduction in CD16 ( Fc gamma RIII) expression. J Immunol 1994; 153:1254-1263.

-34 Davidson D, Miskolci V, Clark DC, Dolmaian G, Vancurova I: Interleukin-10 production after pro-inflammatory stimulation of neutrophils and monocytic cells of the newborn. Comparison to exogenous interleukin-10 and dexamethasone levels needed to inhibit chemokine release. Neonatology 2007;92:127-133.

>35 Luscinskas FW, Kiely JM, Ding H, Obin MS, Hebert CA, Baker JB, Gimbrone MA Jr: In vitro inhibitory effect of IL-8 and other chemoattractants on neutrophil-endothelial adhesive interactions. J Immunol 1992;149: 2163-2171.

36 Harris MC, D’Angio CT, Gallagher PR, Kaufman D, Evans J, Kilpatrick L: Cytokine elaboration in critically ill infants with bacterial sepsis, necrotizing entercolitis, or sepsis syndrome: correlation with clinical parameters of inflammation and mortality. J Pediatr 2005; 147:462-468.

37 Viscardi RM, Lyon NH, Sun CC, Hebel JR, Hasday JD: Inflammatory cytokine mRNAs in surgical specimens of necrotizing enterocolitis and normal newborn intestine. Pediatr Pathol Lab Med 1997;17:547-559.

38 Petrakou E, Mouchtouri A, Levi E, Lipsou N, Xanthou M, Fotopoulos S: Interleukin-8 and monocyte chemotactic protein-1 mRNA expression in perinatally infected and asphyxiated preterm neonates. Neonatology 2007; 91:107-113.

39 Laborada G, Nesin M: Interleukin-6 and interleukin- 8 are elevated in the cerebrospinal fluid of infants exposed to chorioamnionitis. Biol Neonate 2005;88:136-144. 
-40 Krueger M, Nauck MS, Sang S, Hentschel R, Wieland H, Berner R: Cord blood levels of interleukin- 6 and interleukin- 8 for the immediate diagnosis of early-onset infection in premature infants. Biol Neonate 2001;80: 118-123.

-41 Yost CC, Denis MM, Lindemann S, Rubner FJ, Marathe GK, Buerke M, McIntyre TM, Weyrich AS, Zimmerman GA: Activated polymorphonuclear leukocytes rapidly synthesize retinoic acid receptor-alpha: a mechanism for translational control of transcriptional events. J Exp Med 2004;200:671-680.

42 Rashmi R, Bode BP, Panesar N, King SB, Rudloff JR, Gartner MR, Koenig JM: Siglec-9 and SHP-1 are differentially expressed in neonatal and adult neutrophils. Pediatr Res 2009;66:266-271.

43 Garcia-Ramallo E, Marques T, Prats N, Beleta J, Kunkel SL, Godessart N: Resident cell chemokine expression serves as the major mechanism for leukocyte recruitment during local inflammation. J Immunol 2002; 169:6467-6473.

-44 Kallapur SG, Nitsos I, Moss TJ, Polglase GR, Pillow JJ, Cheah FC, Kramer BW, Newnham JP, Ikegami M, Jobe AH: IL-1 mediates pulmonary and systemic inflammatory responses to chorioamnionitis induced by lipopolysaccharide. Am J Respir Crit Care Med 2009;179:955-961.

-45 Tatad AM, Nesin M, Peoples J, Cheung S, Lin $\mathrm{H}$, Sison C, Perlman J, Cunningham-Rundles S: Cytokine expression in response to bacterial antigens in preterm and term infant cord blood monocytes. Neonatology 2008; 94:8-15.

-46 Hatano Y, Kasama T, Iwabuchi H, Hanaoka R, Takeuchi HT, Jing L, Mori Y, Kobayashi K, Negishi M, Ide H, Adachi M: Macrophage inflammatory protein 1 alpha expression by synovial fluid neutrophils in rheumatoid arthritis. Ann Rheum Dis 1999;58:297-302.
7 Smedman C, Gardlund B, Nihlmark K, Gille-Johnson P, Andersson J, Paulie S: ELISpot analysis of LPS-stimulated leukocytes: human granulocytes selectively secrete IL-8, MIP-1beta and TNF-alpha. J Immunol Methods 2009;346:1-8.

48 Chiba K, Zhao W, Chen J, Wang J, Cui HY, Kawakami H, Miseki T, Satoshi H, Tanaka J, Asaka M, Kobayashi M: Neutrophils secrete MIP-1 beta after adhesion to laminin contained in basement membrane of blood vessels. Br J Haematol 2004;127:592-597.

49 Patel DD, Zachariah JP, Whichard LP: CXCR3 and CCR5 ligands in rheumatoid arthritis synovium. Clin Immunol 2001;98: 39-45.

-50 Brennan S, Sly PD, Gangell CL, Sturges N, Winfield K, Wikstrom M, Gard S, Upham JW: Alveolar macrophages and CC chemokines are increased in children with cystic fibrosis. Eur Respir J 2009;34:655-661.

51 Zheng W, Li R, Pan H, He D, Xu R, Guo TB, Guo Y, Zhang JZ: Role of osteopontin in induction of monocyte chemoattractant protein 1 and macrophage inflammatory protein lbeta through the NF-kappaB and MAPK pathways in rheumatoid arthritis. Arthritis Rheum 2009;60:1957-1965.

52 Ley K: Weird and weirder: how circulating chemokines coax neutrophils to the lung. Am J Physiol Lung Cell Mol Physiol 2004; 286:L463-L464.
53 Seghaye MC, Heyl W, Grabitz RG, Schumacher K, von Bernuth G, Rath W, Duchateau $\mathrm{J}$ : The production of pro- and anti-inflammatory cytokines in neonates assessed by stimulated whole cord blood culture and by plasma levels at birth. Biol Neonate 1998;73: 220-227.

54 Fleer A, Krediet TG: Innate immunity: Tolllike receptors and some more. A brief history, basic organization and relevance for the human newborn. Neonatology 2007;92:145157.

55 McColl SR, Paquin R, Menard C, Beaulieu $\mathrm{AD}$ : Human neutrophils produce high levels of the interleukin 1 receptor antagonist in response to granulocyte/macrophage colonystimulating factor and tumor necrosis factor alpha. J Exp Med 1992;176:593-598.

56 Caron JE, La Pine TR, Augustine NH, Martins TB, Hill HR: Multiplex analysis of Tolllike receptor-stimulated neonatal cytokine response. Neonatology 2009;97:266-273.

57 Kollmann TR, Crabtree J, Rein-Weston A, Blimkie D, Thommai F, Wang XY, Lavoie PM, Furlong J, Fortuno ES, III, Hajjar AM, Hawkins NR, Self SG, Wilson CB: Neonatal innate TLR-mediated responses are distinct from those of adults. J Immunol 2009;183: 7150-7160.

58 Haslett C, Lee A, Savill JS, Meagher L, Whyte MK: Apoptosis (programmed cell death) and functional changes in aging neutrophils. Modulation by inflammatory mediators. Chest 1991;99(3 suppl):6S.

-59 Yerkovich ST, Wikstrom ME, Suriyaarachchi D, Prescott SL, Upham JW, Holt PG: Postnatal development of monocyte cytokine responses to bacterial lipopolysaccharide. Pediatr Res 2007;62:547-552.

-60 Zhao J, Kim KD, Yang X, Auh S, Fu YX, Tang $\mathrm{H}$ : Hyper innate responses in neonates lead to increased morbidity and mortality after infection. Proc Natl Acad Sci USA 2008; 105: 7528-7533. 